\title{
SOCIOMETRIA E HABILIDADES SOCIAIS EM ALUNOS DO ENSINO MÉDIO
}

\section{Daniel Bartholomeu}

Doutor em avaliação psicológica pela Universidade São Francisco e docente do Unisal / Americana onde coordena o Laboratório de Psicodiagnóstico e Neurociências Cognitivas. Membro do Labape e do Lepespe (Unesp-Rio Claro) onde realiza seus estudos de pós doutorado.

José Maria Montiel

Doutor em avaliação psicológica com ênfase em neuropsicologia pela Universidade São Francisco e docente da Faculdade Anhanguera de Jundiaí. Membro do Laboratório de Psicodiagnóstico e Neurociências Cognitivas. Membro do Lepespe (Unesp-Rio Claro) onde realiza seus estudos de pós doutorado.

Fernando Pessotto Mestre em avaliação psicológica pela Universidade São Francisco e docente do Unisal / Americana. Membro do Laboratório de Psicodiagnóstico e Neurociências Cognitivas e do Labape.

\begin{abstract}
Resumo
Esta pesquisa teve como objetivo verificar as correlações entre habilidades sociais e aceitação entre os pares tanto para a situação de estudar como de sair. Foram avaliados 45 adolescentes de 16 a 18 anos, todos provenientes de uma escola particular de uma cidade do interior do estado de São Paulo. Foi aplicado o Inventário de Habilidades Sociais e o Questionário Sociométrico de forma coletiva aos alunos previamente autorizados. Foram encontradas apenas correlações significativas entre as medidas sociométricas e o IHS na amostra masculina. A descoberta desse tipo de associação pode fornecer dados úteis no planejamento de programas de intervenção em habilidades sociais com vistas a aumentar a coesão grupal.

Palavras-chave: sociometria, habilidades sociais, evidências de validade.
\end{abstract}

\section{SOCIOMETRY AND SOCIAL SKILLS IN HIGH SCHOOL STUDENTS}

\begin{abstract}
This research aimed to verify the correlations between social skills and aceptance between pairs in study and go out to parties situations. 45 adolescents aged from 16 to 18 years attending at a private school of a city of the interior of São Paulo's state were assessed. We used the Inventário de Habilidades Sociais and the sociometric questionnaire wich were collectively applied to students who were previously autorized by their parents. Only a few significant correlations were identified between the measures in the male sample. This kind of relations can furnish usefull data in the planning of social skills interventions designed to improve group cohesion.
\end{abstract}

Keywords: sociometry, social skills, validity evidence. 


\title{
SOCIOMETRIA Y HABILIDADES SOCIALES EN LOS ESTUDIANTES DE SECUNDARIA
}

\begin{abstract}
Resumen
Esta pesquisa tuvo como objetivo verificar las correlaciones entre las habilidades sociales y aceptación entre los alumnos en las situaciones de estudiar y salir. Se evaluó 45 adolescentes de 16 a 18 años de una escuela particular de una ciudad del interior de São Paulo. Fue administrado el Inventário de Habilidades Sociais y el Questionario Sociométrico de forma colectiva a los alumnos que fueron autorizados. Las correlaciones fueron significativas entre las medidas sociométrica y el IHS en la muestra de los hombres. Estas asociaciones son útiles en el planteamiento de intevenciones con las habilidades sociales para mejorar la coesión grupal.
\end{abstract}

Palabras clave: sociometria, habilidades sociales, evidencias de validadez.

\section{INTRODUÇÃO}

A frequência com que determinados comportamentos são emitidos pelos indivíduos de um grupo tende a constituir um indicador das habilidades que são valorizadas nesse contexto, e por isso pode ser tomado como referência para avaliar o ajuste ou afastamento de um indivíduo das normas e expectativas de seu grupo. O afastamento pode ser resultado tanto de déficits de observação, percepção social, discriminação e controle sobre o próprio comportamento como de atitudes, concepções e valores diferentes do padrão predominante na cultura do grupo (Del Prette \& Del Prette, 1996).

Quando se observa a estrutura detalhada de um grupo, percebe-se a posição ocupada pelos indivíduos e as relações constituídas ao redor de cada um (mais amplo para alguns e mais simples para outros). Este núcleo de relações que representa as relações significativas na vida de uma pessoa foi denominado por Moreno (1993) de átomo social. Dimitrov e Ebsary (1999) complementam salientando que cada indivíduo, ao entrar em um grupo, busca a aceitação e teme ser rejeitado. Esta condição acarreta uma negociação imaginária acerca da individualidade pessoal com a do grupo, buscando uma aproximação das referências nele constituídas.

Esta condição enquadra alguns aspectos de quais variáveis psicológicas investigar para se obter uma compreensão mais ampla do que produz aceitação e rejeição como, por exemplo, as habilidades sociais. Para Del Prette e Del Prette (2001), o termo habilidades sociais é utilizado para designar a existência de diferentes classes de comportamentos no repertório do indivíduo para lidar com as diferentes situações interpessoais. De acordo com os autores, todo e qualquer comportamento inserido em um contexto social é considerado um desempenho 
social, podendo ser aceito ou não, de acordo com as normas, mesmo que implícitas, daquele contexto. Portanto, a competência social é a percepção desta aceitação e a regulação dos comportamentos a fim de se apresentar coerente e funcional com os pensamentos e sentimentos do indivíduo, sendo assim, socialmente aceitos.

Dizer que alguém é competente está vinculado, basicamente, a uma avaliação da qualidade da atuação dessa pessoa em uma dada tarefa. Nesses termos, o conceito de habilidade seria utilizado para designar as habilidades específicas que levam o indivíduo a um comportamento eficaz e competente em uma determinada tarefa. No caso específico das habilidades sociais, o termo "social" se torna um adjetivo delimitando o foco de interesse das habilidades (Caballo, 2003). Para Caballo (1998), o processo para a emissão de uma resposta socialmente aceita é uma complexa cadeia de comportamentos iniciados na percepção de estímulos relevantes, passando pelo processamento das informações, elencando as possíveis respostas, das quais a mais adequada será escolhida, sendo emitida como resposta.

Não existe uma teoria geral que seja consensual entre os pesquisadores das habilidades sociais, sendo essa uma dificuldade apontada para o estudo da variável. Tal dificuldade é decorrente, para Caballo (2003), de uma controvérsia quanto à definição do termo, da dependência do contexto cultural, além da falta de um modelo de pesquisa na área.

Caballo (2003) já salientava que o chamado comportamento socialmente habilidoso é difícil de ser definido, uma vez que depende de contextos sociais distintos. Diante do exposto, ele afirma que, do mesmo modo que não existem formas universalmente corretas de se comportar socialmente, não há um critério absoluto para conceituar habilidade social.

Devem ser considerados, ainda citando Caballo (2003) numa definição adequada de habilidades sociais, tanto o conteúdo quanto as consequências dos comportamentos. O autor destaca que certas definições tendem a considerar o conteúdo das comunicações feitas nos relacionamentos interpessoais, referentes basicamente à expressão de sentimentos e opiniões, enquanto outros focam somente as consequências dos comportamentos ou o reforço social. Uma definição adequada das habilidades sociais deve considerar ambos os aspectos. Define o comportamento socialmente hábil como um conjunto de condutas emitidas, em um determinado contexto interpessoal, que expressam 
sentimentos, desejos, opiniões e direitos, de forma adequada à situação, respeitando os comportamentos alheios e resolvendo os problemas imediatos do contexto, ao mesmo tempo em que minimiza a probabilidade de problemas futuros. Esta foi a definição adotada nesse estudo.

A literatura tende a concordar com 0 fato das habilidades sociais envolverem condutas interpessoais que incluem capacidades específicas, aprendidas e submetidas aos fatores ambientais e pessoais. A conduta social é conceitualizada sobre a base da reciprocidade. Não só a pessoa é influenciada pelas respostas dos demais, mas esse também auxilia na criação de um ambiente social e exerce influência sobre os outros para que esses modifiquem seu comportamento. Diante da própria definição, a existência de um repertório elaborado de habilidades sociais é condição necessária, porém não é a única, para um desempenho socialmente competente. Além da experiência de aprendizagem, ainda existe um conjunto de fatores pessoais (pensamentos, sentimentos, valores pessoais, crenças, planos e metas) que podem facilitar ou dificultar o exercício desse repertório (Caballo, 2003; Del Prette \& Del Prette, 1996)

Portanto, um aspecto que chama bastante a atenção é que a presença das habilidades sociais no repertório do indivíduo não garante que ele apresente sucesso nos relacionamentos interpessoais. De acordo com Caballo (2003), para uma boa qualidade e manutenção de relacionamentos interpessoais saudáveis e duradouros, propiciando bem-estar emocional e minimização de perdas para si e para aqueles que interagem, é preciso que o indivíduo apresente competência social. Essa competência, ainda conforme o autor, caracteriza-se em uma habilidade mais elaborada e consiste em "organizar pensamentos".

Segundo Del Prette e Del Prette (2001) embora a construção de um repertório socialmente hábil possa ocorrer nas relações e interações em contextos naturais sem treinamento formal, como por exemplo na interação entre pais e filhos, irmãos, colegas de escola, amigos, entre outros, comumente falhas podem ocorrer neste processo de aprendizagem, ocasionando déficits significativos em habilidades sociais. Ainda segundo os autores, há evidências crescentes de que déficits nestas habilidades estão correlacionados com fraco desempenho acadêmico, delinquência, abuso de drogas, crises conjugais e desordens emocionais variadas, como transtornos de ansiedade. 
A importância de avaliar o repertório de habilidades sociais, de acordo com Del Prette e Del Prette (2001), se justifica amplamente dada sua relação com a saúde, a satisfação pessoal, a realização profissional e a qualidade de vida. Por isso mesmo, pode constituir um dos focos de uma intervenção educativa ou terapêutica, cuja eficiência e eficácia devem ser aferidas por instrumentos construídos a partir de pesquisas de validação. Piaget (1973) salientava a qualidade da interação que aproxima os indivíduos de um grupo e reflete na atmosfera do mesmo, sendo atribuído a cada membro um papel específico. Este fato ocorre tanto em sala de aula como nos demais grupos.

Outro aspecto a ser considerado nesse processo consiste da aceitação ou rejeição dos colegas serem fatores decisivos para o crescimento acadêmico e pessoal, sendo que a integração das relações humanas aumentaria a motivação para aprender. É necessário que a escola conheça essa dinâmica das relações para compreender como elas afetam a aprendizagem e os comportamentos. Para Morais, Otta e Scala (2001), a aceitação e popularidade têm sido utilizadas comumente como medidas preditoras do relacionamento do aluno com seu grupo de colegas, e o teste sociométrico fornece avaliações bastante adequadas para esse fim.

Nesse contexto, as técnicas sociométricas de fato representaram um grande avanço no estudo das estruturas grupais, na medida em que possibilitaram a estimação das crianças mais aceitas e rejeitadas em uma coletividade, não sendo, no entanto, suficientes para dar conta de explicar todas as condutas específicas responsáveis por esse fato, restringindo-se somente a estabelecer os aceitos e rejeitados. Desse modo, torna-se necessária a determinação de outras variáveis psicológicas implicadas nesse processo de aceitação-rejeição para caracterizar melhor as escolhas feitas pelas crianças ou mesmo que complementem as suas interpretações.

Para Moreno (1972), sociometria é o estudo matemático dos caracteres psicológicos da população, a técnica experimental de métodos quantitativos e o resultado que se obtém ao aplicá-los. Desenvolve uma investigação sistemática sobre a constituição e evolução de grupos e sobre a posição dos indivíduos neles, sempre observando as relações espontâneas de atração e repulsão.

As raízes da sociometria começaram com as experiências de Moreno em 1917, durante a Primeira Guerra Mundial. Para Fox (2002), a criação do teste sociométrico foi uma importante contribuição para a compreensão da dinâmica 
dos grupos. Moreno (1992) define que o teste sociométrico (socius=companheiro; metrum=medida) de um lado enfatiza a medida de características psicológicas inerentes aos contextos sociais a partir de análises quantitativas, de outro, é evidenciado o próprio ser humano na relação. Portanto, complementa (Moreno, 1993) que este instrumento possibilita investigar os vínculos entre as pessoas e mapeá-los possibilitando sua compreensão em função do grupo.

Para Moreno (1972), é possível identificar a estrutura complexa que é a organização de um grupo, mediante a aplicação do teste com crianças. O autor considerava que a sociometria seria o estudo matemático de propriedades psicológicas de uma população. Entretanto, embora o termo sugira mensuração, é o socius e não o metrum que representa seu maior significado, uma vez que é o aspecto qualitativo na estrutura social. Para o autor, tal estrutura é semelhante à atômica, já que se observam padrões de repulsa, atração e indiferença. Ainda de acordo com Moreno (1972), sociometria é a ciência da medida do relacionamento humano.

A sociometria inserida no contexto deste trabalho permite um estudo do inter-relacionamento grupal e em que as habilidades sociais favorecem estas relações. Desta forma se apresenta como um poderoso instrumento, uma vez que nem sempre a é possível identificar com precisão estas configurações reais assumidas pelos indivíduos.

Foi o que verificaram Bartholomeu, Carvalho, Silva, Miguel e Machado (2011) num estudo com o objetivo de investigar associações entre habilidades sociais e a aceitação-rejeição, sendo esta uma variável de relacionamento grupal. Em uma amostra de 126 graduandos de um curso de educação física, foram utilizados o Inventário de Habilidades Sociais (IHS) e uma medida sociométrica para mensurar a aceitação ou rejeição em atividades intra e extra acadêmicas. Os resultados indicaram que, para os homens, a aceitação não foi explicada por nenhuma faceta das habilidades sociais, enquanto que, para as mulheres, foi explicada pela medida de auto-exposição a desconhecidos. Os autores concluem que algumas condutas sociais podem ser empregadas em treinamentos das habilidades sociais a fim de evitar a rejeição entre pares ou mesmo maximizar a aceitação.

Seria de se esperar que o indivíduo mais hábil fosse mais aceito socialmente, conforme se percebe pela definição de habilidades sociais, o que já 
foi demonstrado em alguns estudos da literatura em crianças. Assim, esse trabalho se propõe a investigar tais associações em estudantes do ensino médio. Além disso, a descoberta desse tipo de associação poderia ser utilizada no planejamento de programas de intervenção em habilidades sociais com vistas a aumentar a coesão grupal; em outros termos, possibilitando uma maior aceitação entre os colegas. Por outro lado, do ponto de vista da avaliação psicológica, esse tipo de informação seria considerada uma evidência de validade para o instrumento em questão, o que somaria às evidências já disponíveis para esse instrumento e seria mais um dado que atestaria a eficiência do mesmo. Vale ressaltar que esse tipo de informação, qual seja, da qualidade dos instrumentos de avaliação psicológica disponíveis no Brasil, têm sido amplamente destacada e discutida no Conselho Federal de Psicologia.

\section{MÉTODO}

\section{Participantes}

Participaram da pesquisa 45 adolescentes entre 16 e 18 anos $(M=16$; $\mathrm{DP}=0,61)$, todos provenientes de uma escola particular de uma cidade do interior do estado de São Paulo. Destes, 55,6\% eram do sexo feminino. Instrumentos

\section{Inventário de Habilidades Sociais - IHS-Del-Prette}

O Inventário de Habilidades Sociais (IHS-Del-Prette), desenvolvido por Del Prette e Del Prette (2001), foi construído devido à falta desse tipo de material para avaliação das habilidades sociais no país. Neste instrumento, solicita-se que a pessoa responda a 38 itens descritores de situações de interação social, expressando sua reação a essa quanto à frequência de ocorrência em uma escala de cinco pontos (de nunca à sempre). O estudo das propriedades psicométricas do IHS-Del-Prette foi feito com estudantes universitários por Del Prette, Del Prette e Barreto (1998). A validade baseada na estrutura interna foi estabelecida pela análise fatorial, de critério na comparação de grupos de pré e pós teste com procedimento de intervenção em habilidades sociais e grupos controle e experimental; também estabelecidas em relação aos traços de personalidade e à Escala de Assertividade de Rathus (Del Prette \& Del Prette, 2001). Já a precisão foi tomada pela correlação item-total, sendo que 10 itens da escala final 
apresentam esses valores abaixo do patamar 0,30 proposto por Guilford e Fruchter (1978) como satisfatório para esse tipo de análise.

Os escores do fator enfrentamento com risco (com 11 itens) podem variar de 11 a 55. O fator auto-afirmação na expressão de afeto positivo, com 7 itens, tem pontuações que podem variar de 7 a 35. Na terceira dimensão, conversação e desenvoltura social, com 7 itens, a pontuação pode variar de 7 a 35 . O quarto fator, auto-exposição a desconhecidos ou a situações novas, tem 4 itens e seus escores podem variar de 4 a 20. Finalmente, na dimensão auto-controle da agressividade a situações aversivas, os escores vão de 3 a 15, já que apresenta 3 itens.

Sua aplicação seguiu as instruções do manual e, em sua correção, foram somados os escores referentes a cada dimensão, depois de invertidos os itens indicados no manual. A soma das pontuações dos fatores fornece o escore total do IHS.

\section{Medida Sociométrica}

Essa medida buscou captar a aceitação ou rejeição de uma criança por seus colegas de classe para as atividades de brincar e estudar. Para isso, solicitou-se, primeiramente, que cada aluno indicasse três colegas de sua sala de aula com os quais gostariam de estudar, assim como as razões para a escolha de cada um deles. Dessa forma, o primeiro colega indicado foi considerado com quem ele mais gostaria de estudar e assim sucessivamente. Feito isso, foi solicitado para que indicassem três colegas de sala de aula com os quais não gostariam de estudar, sendo o primeiro escolhido, o mais rejeitado para essa atividade e assim por diante. Nesse caso, novamente indagou-se as razões para a rejeição de cada um dos pares indicados. Essas mesmas perguntas foram feitas também em relação à atividade de brincar. As indicações positivas para cada uma das situações receberam pontos positivos da seguinte forma: +3 para o primeiro escolhido; +2 para o segundo; e +1 para o terceiro. Já para as negativas atribuiu-se -3 para o menos escolhido; -2 para o segundo menos escolhido; e -1 para o terceiro. Com base nessas pontuações, foi encontrada a posição sociométrica de cada um dos alunos pela soma aritmética dos pontos de aceitação e rejeição em cada uma das situações. 
Dessa forma, foram obtidas três medidas. A primeira relativa à aceitaçãorejeição para estudar, a segunda para brincar e a terceira, uma geral que é soma das duas situações, conforme Moreno (1972).

\section{Procedimentos}

A aplicação do Inventário de Habilidades Sociais e do Questionário de Medidas Sociométricas ocorreu somente após a autorização do comitê de ética da Faculdade Politécnica de Jundiaí. Não houve seleção dos participantes em cada uma das salas, já que se dependeu da assinatura dos termos de consentimento pelos pais. Cada sala contava com aproximadamente 30 sujeitos.

Os instrumentos foram aplicados coletivamente em horários préestabelecidos cedidos pelas professoras em cada sala. Inicialmente foi aplicado o IHS, finalizando com o questionário de medidas sociométricas. Optou-se por esta dinâmica já que é o questionário é um instrumento mais simples e didático de ser respondido, considerando assim o cansaço da população da amostra ao responder os testes. Foi comunicado aos participantes que os dados serão mantidos em sigilo. O tempo utilizado para aplicação foi de 50 minutos em cada sala.

\section{RESULTADOS}

Antes de se analisar as correlações entre as medidas estabelecidas, é necessário demonstrar a normalidade das mesmas para identificar a viabilidade do uso de provas paramétricas ou não paramétricas. Essa análise consta na Figura 1.

Para tornar os escores dos fatores do IHS comparáveis, converteu-se as notas deste teste em escores padrão (escores $\mathrm{z}$ ) cuja média é 0 e desvio-padrão, 1. Analisando esses dados, identificou-se pouca dispersão nas medidas do IHS, sugerindo uma variabilidade não muito elevada nesses escores ao redor da média. Já nas medidas sociométricas, a dispersão ao redor da média foi maior, indicando uma variação grande dos alunos em termos de aceitação e rejeição para estudar e sair. 

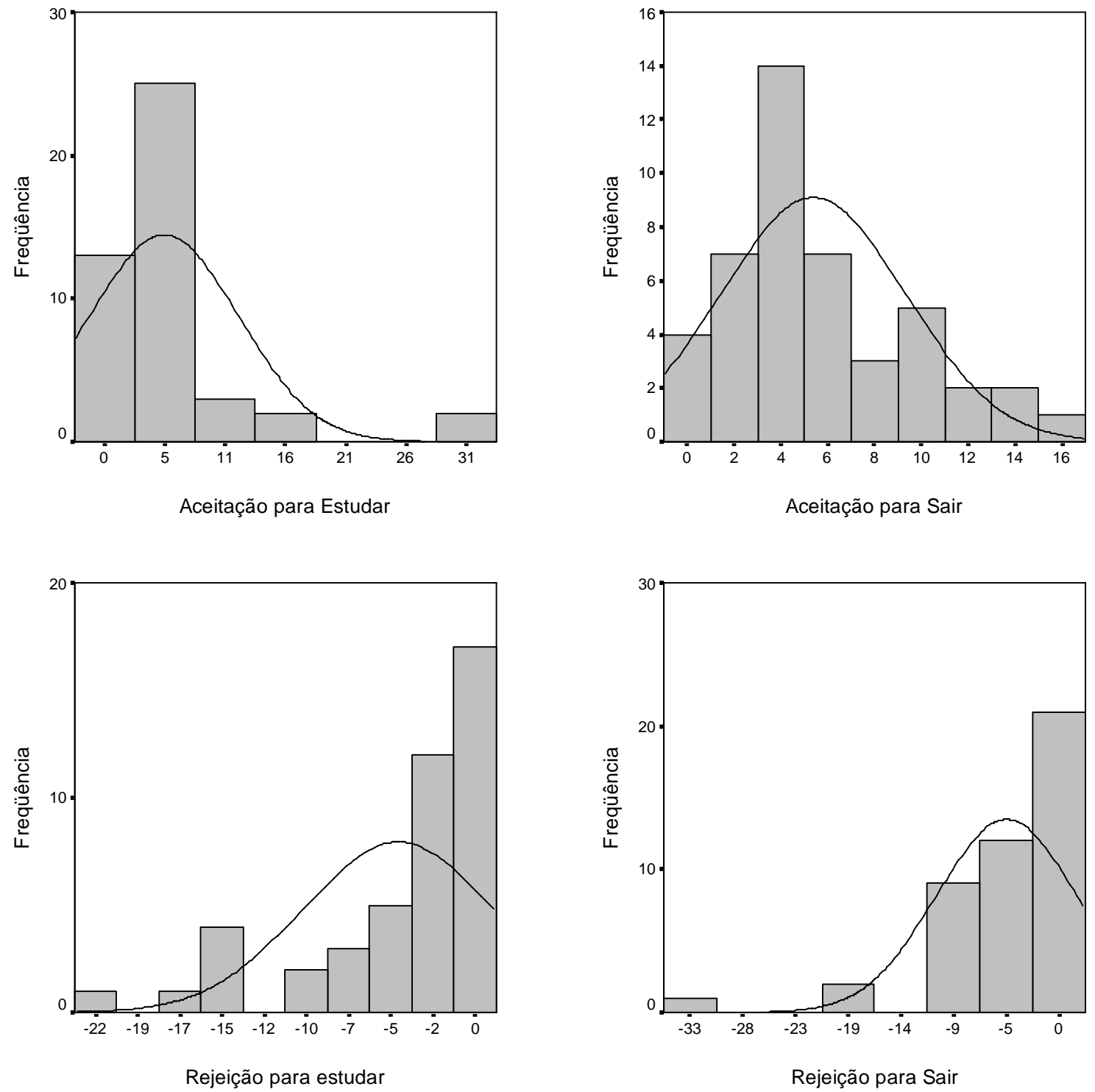

Figura 1.

Distribuição da medida de aceitação e rejeição para estudar e sair $(\mathrm{N}=45)$.

Também os coeficientes de skewness (que identifica assimetria na curva normal) e kurtosis (que indica o acúmulo de pessoas em pontos específicos da distribuição) estiveram dentro de padrões aceitáveis nas medidas do IHS, sugerido que a distribuição das pontuações totais apresentaram uma tendência à normalidade. Por sua vez, as medidas de aceitação e de rejeição para estudar apresentaram valores de skewness e kurtosis acima dos parâmetros esperados, sendo sugestivo de uma elevada assimetria nas distribuições, não se podendo afirmar a normalidade de tais medidas, da mesma forma como rejeição para sair que apresentou uma elevada kurtosis (valores positivos indicam picos na distribuição dos dados, enquanto valores negativos indicam distribuição mais 
abrandada, sua magnitude indica a severidade desses dados; já skewness que estejam fora do intervalo -1 a 1 indicam assimetrias na distribuição). Estas análises são demonstradas na Tabela 1.

Tabela 1.

Estatísticas descritivas das medidas para a amostra de estudantes $(N=45)$.

\begin{tabular}{ccccccc}
\hline & $\begin{array}{c}\text { Aceitação } \\
\text { para } \\
\text { estudar }\end{array}$ & $\begin{array}{c}\text { Aceitação } \\
\text { para sair }\end{array}$ & $\begin{array}{c}\text { Rejeição } \\
\text { para } \\
\text { estudar }\end{array}$ & $\begin{array}{c}\text { Rejeição } \\
\text { para sair }\end{array}$ & IHS Fator 1 & $\begin{array}{c}\text { IHS } \\
\text { Fator 2 }\end{array}$ \\
\hline Média & 5,22 & 5,38 & $-4,4$ & $-4,51$ & 0,3191 & 0,2531 \\
Mediana & 4 & 4 & -2 & -3 & 0,5404 & 0,2402 \\
Moda & 3 & 4 & 0 & 0 & $-1,81$ & 1,42 \\
Desvio & 6,466 & 3,939 & 5,475 & 6,233 & 0,9082 & 0,8103 \\
Padrão & 2,814 & 0,854 & $-1,617$ & $-2,674$ & $-0,537$ & $-0,596$ \\
Skewness & 8,72 & 0,172 & 1,98 & 9,483 & 0,279 & $-0,133$ \\
Kurtosis & 0 & 0 & -22 & -33 & $-1,81$ & $-1,73$ \\
Mínimo & 31 & 16 & 0 & 0 & 2,32 & 1,42 \\
Máximo & IHS Fator & IHS Fator & IHS Fator & Geral & Soma geral & IHS \\
\hline & 3 & 4 & 5 & estudar & sociometrico & Fator 3 \\
\hline Média & 0,1939 & $-0,061$ & 0,0411 & 0,8222 & 0,8667 & 0,1939 \\
Mediana & 0,3237 & 0,0704 & 0,2762 & 1 & 2 & 0,3237 \\
Moda & $-2,24$ & 0,07 & $-0,86$ & 3,00 & $-6,00$ & $-2,24$ \\
Desvio & 1,1325 & 0,8004 & 0,833 & 9,47794 & 8,07521 & 1,1325 \\
Padrão & $-0,159$ & $-0,735$ & $-0,046$ & 0,569 & $-1,833$ & $-0,159$ \\
Skewness & $-0,866$ & $-0,146$ & 1,666 & 2,18 & 6,211 & $-0,866$ \\
Kurtosis & $-0,24$ & $-2,46$ & -22 & -33 & $-2,24$ \\
Mínimo & $-2,24$ & $-2,01$ & $-2,46$ & 28 & 14 & 2,24 \\
Máximo & 2,24 & 1,38 & 2,21 & & &
\end{tabular}

Considerando que nem todas as medidas apresentaram tendência normal, optou-se por se utilizar análises não-paramétricas de dados. Assim, para se investigar a associação entre as medidas obtidas, utilizou-se a prova de correlação de postos de Spearman, com nível de significância de 0,05. Os resultados desta análise por sexo e no geral são apresentados na Tabela 2. 
Tabela 2.

Coeficientes de correlação de Spearman e níveis de significância entre as medidas de aceitação / rejeição para estudar e sair e o geral para ambas as situações e as medidas das dimensões do IHS geral, para o sexo masculino e feminino $(\mathrm{N}=45)$.

\begin{tabular}{|c|c|c|c|c|c|c|c|c|}
\hline & & & $\begin{array}{c}\text { Aceitação } \\
\text { para } \\
\text { estudar }\end{array}$ & $\begin{array}{l}\text { Aceitação } \\
\text { para sair }\end{array}$ & $\begin{array}{c}\text { Rejeição } \\
\text { para } \\
\text { estudar }\end{array}$ & $\begin{array}{c}\text { Rejeição } \\
\text { para } \\
\text { sair }\end{array}$ & $\begin{array}{c}\text { Geral } \\
\text { sociometrico } \\
\text { estudar }\end{array}$ & $\begin{array}{c}\text { Soma geral } \\
\text { sociometrico } \\
\text { sair }\end{array}$ \\
\hline \multirow{11}{*}{$\begin{array}{l}\overline{0} \\
\frac{\pi}{0} \\
\sigma\end{array}$} & IHS & $r$ & $-0,15$ & 0,25 & $-0,16$ & $-0,03$ & $-0,13$ & 0,18 \\
\hline & & $p$ & 0,331 & 0,100 & 0,303 & 0,864 & 0,344 & 0,247 \\
\hline & IHS & $r$ & 0,23 & 0,10 & 0,02 & $-0,07$ & 0,11 & 0 \\
\hline & & $p$ & 0,111 & 0,525 & 0,918 & 0,588 & 0,422 & 0,998 \\
\hline & IHS & $r$ & $-0,02$ & $-0,01$ & $-0,18$ & $-0,08$ & $-0,09$ & $-0,04$ \\
\hline & & $n$ & 0831 & 0054 & מ & Q & 0563 & 0 \\
\hline & IHS & $r$ & $-0,10$ & 0,13 & $-0,13$ & $-0,02$ & $-0,11$ & 0,12 \\
\hline & Fator 4 & & & & & & & \\
\hline & & $p$ & 0,525 & 0,418 & 0,349 & 0,899 & 0,488 & 0,438 \\
\hline & IHS & $r$ & 0,24 & 0,19 & 0,11 & $-0,06$ & 0,25 & 0,10 \\
\hline & & $p$ & 0,117 & 0,210 & 0,426 & 0,644 & 0,091 & 0,492 \\
\hline \multirow{10}{*}{ 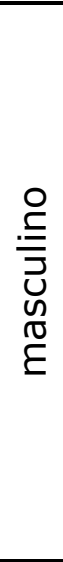 } & ZIHS1 & $r$ & $-0,05$ & 0,18 & 0,04 & 0,31 & 0,09 & 0,35 \\
\hline & & $p$ & 0,799 & 0,419 & 0,822 & 0,168 & 0,706 & 0,132 \\
\hline & ZIHS2 & $r$ & 0,52 & 0,31 & 0,44 & 0,30 & 0,49 & 0,26 \\
\hline & & $p$ & 0,011 & 0,163 & 0,050 & 0,204 & 0,024 & 0,274 \\
\hline & ZIHS3 & $r$ & $-0,24$ & $-0,31$ & $-0,19$ & $-0,16$ & $-0,30$ & $-0,35$ \\
\hline & & $p$ & 0,284 & 0,166 & 0,392 & 0,487 & 0,179 & 0,133 \\
\hline & ZIHS4 & $r$ & $-0,16$ & $-0,01$ & $-0,39$ & $-0,19$ & $-0,35$ & $-0,13$ \\
\hline & & $p$ & 0,463 & 0,951 & 0,091 & 0,434 & 0,135 & 0,593 \\
\hline & ZIHS5 & $r$ & 0,20 & 0,09 & 0,51 & 0,23 & 0,52 & 0,26 \\
\hline & & $p$ & 0,365 & 0,666 & 0,023 & 0,305 & 0,020 & 0,275 \\
\hline \multirow{10}{*}{ 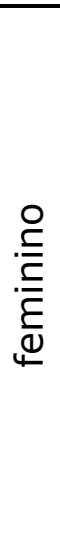 } & ZIHS1 & $r$ & $-0,28$ & 0,26 & $-0,35$ & $-0,30$ & $-0,32$ & 0,01 \\
\hline & & $p$ & 0,168 & 0,209 & 0,088 & 0,129 & 0,104 & 0,966 \\
\hline & ZIHS2 & $r$ & $-0,01$ & $-0,07$ & $-0,19$ & $-0,22$ & $-0,09$ & $-0,19$ \\
\hline & & $p$ & 0,909 & 0,698 & 0,333 & 0,259 & 0,679 & 0,368 \\
\hline & ZIHS3 & $r$ & 0,04 & 0,15 & $-0,19$ & 0,11 & 0 & 0,18 \\
\hline & & $p$ & 0,829 & 0,433 & 0,369 & 0,614 & 0,985 & 0,377 \\
\hline & ZIHS4 & $r$ & $-0,01$ & 0,28 & 0 & 0,10 & 0,06 & 0,31 \\
\hline & & $p$ & 0,946 & 0,178 & 0,972 & 0,642 & 0,737 & 0,126 \\
\hline & ZIHS5 & $r$ & 0,04 & 0,07 & 0 & $-0,19$ & 0,07 & $-0,04$ \\
\hline & & $p$ & 0,796 & 0,745 & 1 & 0,362 & 0,697 & 0,836 \\
\hline
\end{tabular}

As correlações entre essas medidas com a amostra geral não foram significativas entre as medidas sociométricas e do IHS. Separadamente por sexo, 
a medida do fator auto-afirmação na expressão de afeto positivo associou-se positiva e significativamente com aceitação e rejeição para estudar e o sociométrico geral para estudar. Esses dados indicam que os meninos que apresentaram habilidades para lidar com demandas de expressão de afeto positivo e de afirmação da auto-estima, mesmo com um risco mínimo de reação indesejável foram mais aceitos e menos rejeitados na situação de estudar. Ao mesmo tempo, a dimensão autocontrole da agressividade em situações aversivas associou-se positiva e significativamente com rejeição para estudar e sociométrico geral para estudar. Com base nisso, pode-se sugerir que os garotos que apresentaram capacidade de reagir a estimulações aversivas do interlocutor com razoável controle da raiva e da agressividade, expressando-se de forma socialmente competente e controlando seus sentimentos negativos, foram menos rejeitados para estudar. No sexo feminino, nenhuma das medidas foram associadas significativamente, sendo os resultados encontrados, restritos ao sexo masculino.

\section{DISCUSSÃO}

A hipótese aventada neste estudo é que haveria correlação significativa entre a habilidade social (medida pelo IHS) e a aceitação entre os pares, (analisado pelas medidas sociométricas), tanto para a situação de estudar como de sair. Na amostra geral, os coeficientes de correlação não foram significativos entre os testes aplicados, porém existe uma correlação entre alguns fatores quando se divide a amostra por sexo.

Nos testes dos meninos foram encontradas correlações entre o IHS e as Medidas Sociométricas. Isso se deu na associação da medida auto-afirmação e expressão do afeto positivo com um alto nível de aceitação para estudar e um baixo nível de rejeição para estudar, e a dimensão autocontrole da agressividade em situações aversivas associou-se com uma baixa rejeição para estudar.

Conforme Del Prette e Del Prette (1996) a frequência com que determinados comportamentos são emitidos pelos indivíduos de um grupo ou contexto social constitui um indicador das habilidades efetivas e valorizadas nesse contexto. A associação encontrada entre as medidas do IHS e das medidas sociométricas pode ser uma evidência das características valorizadas pela população do sexo masculino na amostra utilizada para aplicação. 
Caballo (1993) realizou pesquisas no âmbito dos componentes das habilidades sociais. Segundo o autor, existem componentes de condutas que podem ser identificados e mensurados. Ressaltam-se duas divisões dos componentes, a saber: 1) conduta que se subdivide em não verbais, como os gestos e expressões faciais; por exemplo, quando se sorri ao encontrar um conhecido pelo caminho; componentes paralinguísticos, no volume e no tom da voz; componentes verbais, como elogios e agradecimentos; como o conteúdo geral de uma verbalização e componentes mistos mais gerais, como o afeto ou o saber escutar; e 2) componentes cognitivos, que consideram as percepções e avaliações do indivíduo sobre os acontecimentos, situações e os estímulos que envolvem sua concepção de mundo e de si mesmo, neste caso seriam considerados fatores importantes à idade, o sexo e a cultura dos indivíduos.

Ponderando o fato de que o conhecimento do repertório social da criança é bastante escasso, Del Prette e Del Prette (2005) sugeriram sete classes de habilidades consideradas prioritárias no desenvolvimento de treinamentos e avaliações de habilidades sociais, acrescentando-se ao modelo anterior as categorias fazer amizades, com comportamentos de fazer perguntas, elogiar, aceitar elogios, oferecer ajuda, apresentar-ser, cumprimentar, dentre outros; solucionar problemas interpessoais que envolvem pensar antes de tomar decisões, reconhecer e nomear problemas e identificar e avaliar possíveis alternativas de solução; e habilidades sociais acadêmicas que abarcam seguir regras, prestar atenção, ignorar interrupções feitas pelos colegas, aguardar a vez para falar, oferecer, solicitar e agradecer ajuda, reconhecer a qualidade do outro e cooperar nas discussões. Tem-se então que o comportamento social é uma conjunção de dados inatos e processos de socialização, que ocorrem a partir do conjunto de pensamentos, afetos, ações e atitudes em direção a um grupo social ou ao próprio sujeito (Caballo, 1993).

No fator auto-afirmação na expressão de afeto positivo (IHS), o risco de reação indesejável de outrem é mínimo, ou seja, a amostra emite um comportamento que tem grande probabilidade de ser aceito no meio social, quando se é cordial com todos, se tem uma fala agradável, uma boa escuta, ajuda o outro em situações publicas, etc. O fator auto-afirmação correlacionouse com aceitação para estudar avaliada nas medidas sociométricas.

Porém, este mesmo fator não foi correlacionado com o fator enfrentamento e auto-afirmação com risco (IHS), no qual se reúnem situações em que há 
possibilidade de rejeição, réplica ou de oposição (Del Prette \& Del Prette, 2001). Este dado levanta a possibilidade dos sujeitos do sexo masculino, avaliados na amostra, não possuírem repertório para lidar com situações de risco onde possa haver rejeição. Sendo assim, identifica-se a necessidade de uma intervenção para desenvolvimento no treino das habilidades identificadas no fator enfrentamento e auto-afirmação com risco, para que as pessoas do sexo masculino possam melhorar sua aceitação no meio.

No fator autocontrole da agressividade em situações aversivas encontrou-se associação com uma baixa rejeição para estudar. Vale ressaltar que isto não quer dizer que a população da amostra não se expressa, mas que o fazem de forma socialmente competente, ou seja, sem agressividade, por exemplo, em situações onde se é preciso lidar com críticas dos pais, com chacotas ou brincadeiras ofensivas. As pessoas desta amostra com comportamentos citados acima obtiveram uma baixa rejeição para estudar. Sugere-se que isto se deve ao fato de se expressar de maneira mais competente, pois assim o risco de rejeição é menor.

Neste presente instrumento, identifica-se que tanto no fator de autoafirmação na expressão de afeto positivo, quanto no fator autocontrole da agressividade em situações aversivas, a população da amostra não está exposta a situações onde haja risco de rejeição por emitir comportamentos que possam não ser aceitos. Sendo assim, levanta-se a hipótese de que, em uma situação onde o adolescente enfrente risco por sua falta de comportamentos adequados para aquele contexto, ele possa ser rejeitado.

Acredita-se que, em relação a esta possível inabilidade social em enfrentar os riscos, vale sugerir que intervenções devem ser propostas através de treinos específicos de habilidade social, uma tentativa direta e sistemática de ensinar estratégias e habilidades interpessoais aos indivíduos, com a intenção de melhorar sua competência interpessoal e individual nas situações de interação sociais. Conforme Curran (apud Caballo, 2007), deve-se descrever os comportamentos socialmente adequados e suas repercussões na vida e nas relações dos indivíduos, de como se é possível discordar de colegas ou autoridades sem que isto seja interpretado de maneira inábil.

É relevante salientar que há uma estrutura neste processo de treinamento em habilidades sociais, em que se emprega a modelação, treino de assertividade e reestruturação cognitiva, o ensaio comportamental, a retroalimentação, o 
feedback e reforçamento, entre outras. Assim como técnicas de treinamento em grupo, conforme Caballo (2007).

Descrevendo-se em etapas, a primeira seria identificar a necessidade do sujeito, que no caso, seriam os comportamentos citados anteriormente nesta discussão encontrada na amostra do sexo masculino em situações de enfrentamento com risco de rejeição. Posteriormente é relevante que o sujeito entenda e distingua as respostas que ele pode emitir que podem ser assertivas, não assertivas e agressivas. A terceira etapa abordaria uma reestruturação cognitiva dos modos de pensar considerados incorretos, para posteriormente se iniciar o ensaio comportamental das respostas socialmente adequadas em determinadas situações (Caballo, 2007).

A validade concomitante do IHS foi medida por meio de uma análise entre os resultados deste inventário e das medidas sociométricas. Foi constatado no presente trabalho que este inventário de habilidades sociais não apresenta validade concorrente com as medidas sociométricas, quando a análise é feita com a amostra geral, uma vez que não se apresentam correlações significativas. Conforme Anastasi e Urbina (2000), a validade de um teste pode ser identificando os construtos principais e seu desempenho em determinada situação e, posteriormente, criar ou escolher testes que avaliam os construtos pertinentes.

Separando-se as amostras por sexo, encontra-se concomitância entre IHS e medidas sociométricas restritos ao sexo masculino, nos fatores auto-afirmação na expressão do afeto positivo com associação positiva e significativa com a aceitação para estudar, assim como foram encontradas associações nos fatores autocontrole da agressividade em situações aversivas com baixa rejeição para estudar, o que indica a validade do teste. Ressalta-se que, com o sexo feminino, não foram encontradas associações significativas entre os testes.

\section{CONSIDERAÇÕES FINAIS}

Cabe trazer a importância dos resultados obtidos neste instrumento de pesquisa, e de como os testes de habilidades sociais podem correlacionar-se com outros testes a fim de se encontrar associações significativas e positivas para se validar os testes. Além disso, pode-se estruturar, se necessário em caso de déficits encontradas na população da amostra, treinos específicos pra o desenvolvimento de habilidade social, diminuindo qualquer prejuízo que possa 
ser significativo para esta população. Sugere-se que outras dimensões possam ser avaliadas através de novas pesquisas, correlacionando o IHS com outros testes e questionários, assim como se aprofundar mais nas questões levantadas e encontradas neste presente trabalho.

\section{REFERÊNCIAS}

Anastasi, A. \& Urbina, S. (2000). Testagem psicológica. Porto Alegre: ArtMed Editora.

Bartholomeu, D., Carvalho, L. F., Silva, M. C. R., Miguel, F. K., \& Machado, A. A. (2011). Aceitação e Rejeição entre pares e habilidades sociais em universitários. Estudos de Psicologia (UFRN), 16(2), 155-162.

Caballo, V. E. (1993). La multidimensionalidad conductual de las Habilidades Sociales: Propiedades psicométricas de una medida de autoinforme. EMESM. Psicología Conductual, 1, 221-231.

Caballo, V. E. (1998). Manual para el tratamiento cognitivo-conductual de los transtornos psicológicos: Formulation clinica, medicina conductual $y$ trastornos de relación, vol. 2. Madrid: Siglo XXI.

Caballo, V. E. (2003). Manual de avaliação e treinamento das habilidades sociais. São Paulo: Santos.

Caballo, V. E. (2007). Manual de técnicas de terapia e modificação do comportamento. São Paulo: Santos. $2^{a}$ reimpressão.

Del Prette, Z. A. P. \& Del Prette A. (1996). Habilidades sociais: uma área em desenvolvimento. Psicologia: Reflexão e Crítica, 9, 287-309.

Del Prette, Z. A . P. \& Del Prette, A . (1996). Habilidades envolvidas na atuação do psicólogo escolar/educacional. Em: Wechsler, S. (Org.). Psicologia: Pesquisa, Formação e Prática. Campinas: Alínea, 139-156.

Del Prette, Z. A. P. \& Del Prette, A. (2001). Inventário de Habilidades Sociais (HIS-Del-Prette): Manual de aplicação, apuração e interpretação. São Paulo: Casa do Psicólogo.

Del Prette, Z. A. P., \& Del Prette, A. (2005). Psicologia das habilidades sociais na infância: Terapia e educação. Petrópolis, RJ: Vozes.

Del Prette, A., Del Prette, Z. A. P., \& Barreto, M. C. M. (1999). Habilidades sociales en la formación del psicólogo: Análisis de un programa de intervención. Psicología Conductual (Espanha), 7, 27-47. 
Dimitrov, V. \& Ebsary, R. (1999). Autopoiese intrapessoal. São Paulo: IECPS. Disponível em: <http://www.geocities.com/complexidade/intrap.html>. Acesso em 28 Fev. 2008.

Fox, J. (2002). O essencial de Moreno: Textos sobre psicodrama, terapia de grupo e espontaneidade. São Paulo: Ágora.

Guilford, J. P., \& Fruchter, B. (1978). Fundamental statistics in psychology and education (6th ed.). New York: McGraw-Hill.

Morais, M. L. S., Otta, E., \& Scala, C. T. (2001). Status sociométrico e avaliação de características comportamentais: um estudo de competência social em pré-escolares. Psicologia: Reflexão e Crítica, 14, 119-131.

Moreno, J. L. (1972). Fundamentos de la sociometria. Buenos Aires: Editorial.

Moreno, J. L. (1992). Quem sobreviverá? Fundamentos da sociometria, psicoterapia de grupo e sociodrama. Goiânia: Editora Dimensão. Vol. 1.

Moreno, J. L. (1993). Psicodrama. São Paulo: Ed. Cultrix.

Piaget, J. (1973). Estudos sociológicos. Rio de Janeiro: Fiorense.

Contato: d_bartholomeu@yahoo.com.br, montieljm@hotmail.com, fernandopessotto@gmail.com

Recebido em: 21/12/2011

Revisado em: 28/12/2011

Aceito em: 30/12/2011 